\title{
Workplace Spirituality, Job Satisfaction and Organizational Citizenship Behaviors: A Theoretical Model
}

\author{
Shibani Belwalkar ${ }^{1} \&$ Veena Vohra ${ }^{1}$ \\ ${ }^{1}$ NMIMS, India \\ Correspondence: Shibani Belwalkar, NMIMS, India. E-mail: shibani.belwalkar@live.com
}

Received: June 7, 2016

Accepted: June 18, 2016

Online Published: July 18, 2016

doi:10.5539/ijbm.v11n8p256

URL: http://dx.doi.org/10.5539/ijbm.v11n8p256

\begin{abstract}
Workplace spirituality has steadily been gaining attention in the last couple of years. Many researchers have investigated the role of "workplace spirituality" with the aim of generating research data that would firmly entrench this construct as vital in the workplace. This article proposes the relationships between workplace spirituality, job satisfaction and organizational citizenship behaviors. It examines the relationship between three workplace spirituality components-meaning and purpose in work, recognition of an inner life or spirit and interconnectedness with the various forms in which organizational citizenship behaviours manifest, mediated by the job satisfaction experienced by the employees. This study can provide significant inputs to promote managerial effectiveness, change management, leadership, holistic performance and growth of organizations, through environments which promote workplace spirituality.
\end{abstract}

Keywords: workplace spirituality, job satisfaction, organizational citizenship behaviors, theoretical model

\section{Workplace Spirituality}

The extraordinary attention received by Spirituality in the workplace literature since the 1990's is proof of its importance. The phenomenon of workplace spirituality is described as the experience of an inner life that nourishes, and is nourished by meaningful experiences that take place in context of the workplace (Ashmos \& Duchon, 2000). Past research highlights why it is difficult for employees to have a separate 'spiritual' and 'work life' (Zimmerman, 2004). Employees want to infuse their lives with deeper meaning (Hansen \& Keltner, 2012). Because people spend a majority of their life at work and often derive their social identity from their workplace, what happens to them at work is important for their mental and physical well being-a desire for deeper relationships and a sense of greater purpose. Van Dyne, Graham, and Dienesch (1994) have gone one step ahead and suggested through their research that employees are encouraged to demonstrate greater extra-role, non-mandated performance as a result of their experiencing a strong sense of connection with their organization; a derivation of a sense of meaning and purpose in their daily work.

Giacalone and Jurkiewicz (2003) defined workplace spirituality as "a framework of organizational values that is evidenced in the culture that promotes employees experience of transcendence through work processes facilitating their sense of being connected to others in a way that provides feelings of completeness and joy" ( $\mathrm{p}$. 137).

An examination of the definitions of spirituality throw out several common elements, the most common of them being a desire to live by values which transcend the immediate self needs, deep empathy with all of that has life, and the willingness to connect with a higher power, or the giver/the source of life (Krishnakumar \& Neck, 2002). Giacalone and Jurkiewicz, (2003), define and view 'spirituality as a framework of organizational values evidenced in the culture that promotes employees' experience of transcendence through the work process, facilitating their sense of being connected to others in a way that provides feelings of completeness and joy.' In other words, spirituality is a search for inner identity, connectedness and transcendence (Kinjerski \& Skrypnek 2004).

This article references three core recurring components of workplace spirituality: inner life, interconnectedness and sense of purpose.

\subsection{Inner Life}

Mahakul (2015) has described Inner life as the recognition that there exists a soul, in all human beings. This translates into the reference of a power which surpasses the immediate physical self and transcends the ego. 


\subsection{Purpose and Meaning}

Meaning can be derived through the experience of self-purpose and significance (Overell, 2008). A person may find gainful direction in one's work through the feeling of harmony and oneness with such purpose (Overell, 2008). Meaning and purpose at the workplace involves the acceptance that employees want to be involved in work that gives meaning to their lives. It is the recognition that people have inner motivations and desires to be involved in activities that give greater meaning to life.

\subsection{Interconnectedness}

Interconnectedness, or in other words a sense of community, is well referenced in the literature of spirituality. Stamp (1991; p.80) suggested that spirituality is "an awareness within individuals of a sense of connectedness that exists between inner selves and the world." Chappel (1994) states that when employees share values, and understand a common meaning and purpose, they will find a strong connection with their workplace. Mitroff and Denton (1999; p.83) endorse Chappel's view, as they state that spirituality is "the basic feeling of being connected with one's complete self, others, and the entire universe."

\section{Workplace Spirituality Outcomes}

Workplace Spirituality can lead to several desired outcomes in the workplace, including worker motivation, organizational performance and job satisfaction (Krishnakumar \& Neck, 2002). Organizational citizenship behaviors, according to Pawar (2009), can be enhanced by incorporating spirituality into the workplace. Pawar (2009) in his study of workplace spirituality and work attitudes, built on the research of Milliman et al. (2003) in which he found significance in the hypothesized relationships between workplace spirituality and job satisfaction.

Looking at the definition of job satisfaction, Smith (1955) suggested that it reflects the employee's judgment of how well his job on the whole is satisfying his various needs. It has also been stated that greater job satisfaction is likely to lead eventually to more effective functioning of the individual and the organization as a whole. Brown (2003) states that for any effective and successful organization, there is a great need of job satisfaction, a congenial and healthy organizational climate and constructive behavioral aspects amongst workforce. Building on Brown's view, Sanders et al. (2005) state that 'workplace spirituality involves the process of encouraging employees to feel connected to a network beyond themselves, by fostering a sense of community in the work-place and that that this sense of community will lead to employees experiencing more satisfaction with the organization'(p. 46).

A person's well-being is determined to a large extent by the meaning and purpose in living (or life satisfaction) (Zika \& Chamberlain, 1992). This proposition holds that job satisfaction is to a large extent a manifestation of life meaning, life satisfaction and thus a manifestation of spirituality. Therefore, it is safe to then assume that experiencing life satisfaction through one's work may lead to personally valuing outcomes at the workplace.

Job satisfaction has been linked with several important organizational outcomes such as organizational citizenship behavior (Bateman \& Organ, 1983). Organ (1988), examined the relationship between job satisfaction and helping behaviors, also referred to as Organizational citizenship behaviors, and found them to have a significant impact on the organization.

As early as 1978, Katz and Kahn had highlighted the importance of organizational citizenship in organizations. Organ defined organizational citizenship behaviors as "individual behavior that is discretionary, not directly or explicitly recognized by the formal reward system, and that in the aggregate promotes the effective functioning of the organization"(Organ,1988).

Several components of OCB have been postulated by academics, viz loyal boosterism, cheerleading, self development, etc. Some researchers choose to further classify OCB dimensions as OCBI- OCB directed to the individuals and OCBO- OCB directed to the organizations. Literature highlights 5 major commonly identified and agreed upon constructs:

- Altruism: the act of helping others

- Courtesy: being polite and preventing conflict

- Conscientiousness: doing more than just the minimum; attention to detail

- Civic Virtue: showing interest and involvement (e.g. keeping up to date) with the organization; defend organizational policies and practices and defend the organization when challenged

- Sportsmanship: tolerating less-than-ideal conditions; accepting of changes and performs requests without complaints 
Research has laid out strong arguments in support of a relationship between the employees experience of a strong sense of connection with their organization, a derivation of a sense of meaning and purpose in their daily work (Van Dyne, Graham, \& Dienesch, 1994) and their desire to demonstrate greater extra-role, non-mandated performance as a result of this experience. Experiencing a connection with their workplace, encourages the employee to go beyond the identified 'in-role' behaviors to demonstrate 'extra-role' behaviors, doing things that work in favor of the organization or the work unit (conscientiousness, altruism, civic virtue, sportsmanship and courtesy). Based upon this suggested relationship, it could be inferred that should managers in organizations encourage employees to experience greater meaning and purpose and connection, employees could be encouraged to engage in extra-role behavior. It does seem fair to propose that those employees who experience harmony at the workplace, may try extra hard to achieve organizational objectives.

\section{Workplace Spirituality-Job Satisfaction-OCB: A Model}

Based on the arguments laid above, it may be safe to posit here that one may inspect the stated relationships between workplace spirituality and job satisfaction, and job satisfaction with organizational outcomes such as $\mathrm{OCB}$, to evaluate valuable theoretical explanations on the relationship between job satisfaction and workplace spirituality. An independent study conducted by Sharma, Bajpai and Holani in 2011 in Punjab (India), showed $\mathrm{OCB}$ as an outcome of job satisfaction, whilst in a study done by Gupta, Kumar \& Singh in 2013 on governmental employees in Punjab, workplace spirituality was seen to positively impact job satisfaction.

This article contributes to literature by looking into workplace spirituality and its relationship with job satisfaction and organizational citizenship behaviors (OCBs). This is based upon suggested individual relationships between the three variables in discussion (viz. Workplace Spirituality, Job satisfaction, \& OCB).

As workplace spirituality dimensions fulfill employees' higher order and spiritual needs (Fry et al., 2001), they should induce a more favorable employee affective response. Thus, there should be a positive relationship between workplace spirituality dimensions and job satisfaction. Milliman, Ferguson, Tricket \& Condemi (1999) proposed that an organization that promotes a sense of community will have a more satisfied and motivated workforce. Studies have shown that when employees feel satisfied with their activities at work, they show positive intentions to stay in the organization (Randolph, 2005). Robert, Young and Kelly (2006), and Komala and Ganesh (2007) studied the relationship between workplace spirituality and job satisfaction and found a positive relationship between the two. Research has suggested that where spirituality is practiced at work, there is a positive effect on employee job satisfaction (Chawla \& Guda, 2010).

It can be posited that the literature supports the current hypothesis that the workplace spirituality components of Inner life, interconnectedness and meaning and purpose will have a positive relationship with the Job satisfaction experienced by employees.

\subsection{Job Satisfaction and $O C B$}

Fredrickson's (2004) 'Broaden and Build theory' advocates that the experiences of positive emotions prompt individuals to engage with their environments and partake in activities, many of which were evolutionarily adaptive for the individual, its species, or both. Building on this theoretical foundation, it is fair to assume that

Past researchers, including Bateman \& Organ (1983) and Smith, Organ \& Near, 1983 have found a significant relationship between Job Satisfaction and OCB in their respective studies. Karambayya (1989) analyzed 18 work groups across 12 different organizations comprising mainly professional executives, and examined the relationships between work unit performance and satisfaction and members' citizenship behaviors. The findings showed that members of work units that were rated as having higher levels of performance and satisfaction were generally found to display higher levels of citizenship behavior than were members of work units that exhibited lower levels of performance.

\subsection{Workplace Spirituality and $O C B$}

According to Krishnakumar and Neck (2002), "fostering spirituality will lead to the employees feeling complete when they come to work". Nearly all academic definitions note that spirituality involves a sense of wholeness, transcendence, and that of being a whole and integrated person. According to Duchon and Plowman (2005), the whole self includes the spiritual self and workplaces that enable the expression of spirit are "receptive to the 'entire' or whole person, and as such, may be more productive than workplaces where spirit is ignored".

Though independent research is being continually conducted on each of these knowledge domains, there is a growing body which is also highlighting the possible relationships between employees demonstrating OCB or greater extra-role performance, as a result of them experiencing a strong connection to their organization and upon finding a sense of meaning and purpose in their daily work (Van Dyne, Graham, \& Dienesch, 1994). In 
other words, this is suggestive of a relationship between workplace spirituality and increased commitment to organizational goals including organizational citizenship behaviors (Kinjerski \& Skrypnek, 2004).

Whereas the link between spirituality and wellbeing is well known, researchers are now expanding the view to include positive outcomes for organizations. Whilst some research has analyzed linear relationships between predictor and outcomes, some have studied the role of mediators. For example, Liu (2008) established a positive relationship between transcendental leadership and OCB through the mediator of workplace spirituality. Setiyawati and Abdul Rehman (2007) in their study exploring the spirituality and personality correlates of OCB recognized that meaning of life had a positive significant impact on OCB.

In line with creating an open and learning organization, a spiritual climate too allows workers to be fully engaged. When workers are fully engaged, when they and their managers have common values and a shared sense of purpose, their daily work would be imbued with deeper meaning, (Kinjersk \& Skrypnek, 2005) which leads to satisfaction and fulfillment, and the desire to engage in behaviors for the benefit of the organization. It also appears that individuals in development focused organizations might react more favorably to using OCBs than individuals in results-focused organizations. (Gelfand, Erez, \& Aycan, 2007), which can indicate a likelihood of workplace spirituality leading to OCBs, as workplace spirituality creates an open, free and expressive/ developmental atmosphere for employees to function in.

\section{Proposed Model}

This objective of this article is to propose a model of the relationship between the constructs: spirituality at work (i.e. the independent variable) and organizational citizenship behaviors (OCBs) (i.e. the dependent variable), and to explore the possibility of the mediating effects of Job satisfaction. There is currently a dearth of studies linking workplace spirituality to the outcome of organizational citizenship behaviors.

Literature review on workplace spirituality as discussed above, has linked job satisfaction as an outcome. On the other hand, research on OCB has indicated that job satisfaction is an antecedent to the display of OCB at the workplace. In effect, workplace spirituality leads to job satisfaction and job satisfaction leads to OCB. This research is an attempt to link all three variables, and study the possibility of such a relationship, wherein job satisfaction mediates the demonstration of $\mathrm{OCB}$, as a result of experiencing workplace spirituality.

However, there is a dearth of such empirical research linking the construct of spirituality at work with OCBs. By introducing the various dimensions of the construct of spirituality at work, this study hopes to derive insights and greater understanding into the hypothesized relationships between workplace spirituality and OCBs.

Independent Variable $\quad$ Mediator Dependant Variable

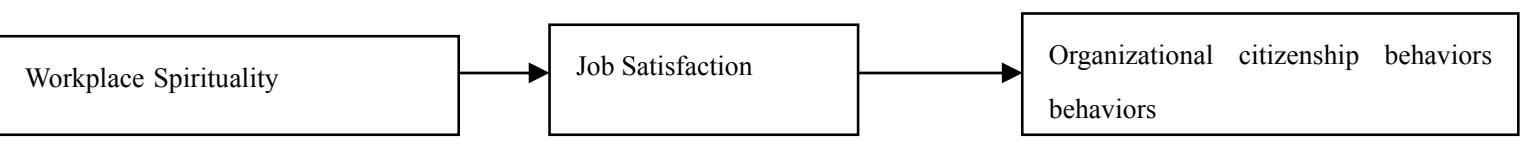

Figure 1. The research model proposed

\subsection{Proposition}

The relationships in the Model expressed can be investigated as hypotheses.

The relationship between workplace spirituality and job satisfaction was found to be positively significant as studied by Altaf and Awan (2011). It has been suggested that workplace spirituality is an important factor that increases employees' happiness (Jurkiewicz \& Giacalone, 2004), and when employees see that appropriate situations are provided in workplace, they try harder than before to reach organizational objectives (Rastgar, 2012). Building on these studies, the researcher has studied the variables of Workplace Spirituality - independent variable, OCB - Dependent variable, Job satisfaction- mediating variable.

Accordingly, the researcher states the following propositions:

H1. A positive relationship would be found between the experience of interconnectedness at the workplace and the Organizational Citizenship Behaviors demonstrated by employees, mediated by their job satisfaction.

H1a. A positive relationship would be found between the experience of interconnectedness at the workplace and the OCB demonstrated by employees.

H1b. A positive relationship would be found between the experience of interconnectedness and the job 
satisfaction experienced by employees.

H2. A positive relationship would be found between the experience of an inner life at the workplace and the Organizational Citizenship Behaviors demonstrated by employees, mediated by their job satisfaction.

H2a. A positive relationship would be found between the experience of an inner life and the OCB demonstrated by employees.

H2b. A positive relationship would be found between the experience of an inner life and the job satisfaction experienced by employees

H3.A positive relationship would be found between the experience of meaning and purpose at the workplace and the Organizational Citizenship Behaviors demonstrated by employees, mediated by their job satisfaction.

H3a. A positive relationship would be found between the experience of meaning and purpose at the workplace and the OCB demonstrated by employees.

H3b. A positive relationship would be found between the experience of meaning and purpose and the job satisfaction experienced by employees.

H4. A positive relationship would be found between Job Satisfaction and the OCB demonstrated by employees at the workplace.

\subsection{Importance of Study}

A critical component of success for organizations today is the behavior of their people. When employees are able to display organizational citizenship behaviors (OCBs), they are in effect contributing positively to the organizations objectives. Researchers have theorized that the effectiveness of organizations is likely to be enhanced when employees go above and beyond the call of duty to aid fellow workers and achieve organizational goals (Organ, 1988). The importance of OCBs is reflected in the large volume of research directed at understanding its antecedents (Bukhari, 2008). As a result of the increasing interest in the study of OCBs, researchers have looked into the possible antecedents to the exhibition of such (desirable) extra-role behaviors by employees (Rastgar, 2012). OCBS are identified as one of the lowest cost and best ways to encourage effectiveness and competitive advantage (Nemeth \& Staw, 1989). Managerial productivity may rise (MacKenzie et al., 1993; Podsakoff \& MacKenzie, 1994) through OCB, as more skilled or efficient workers will help newcomers to come up to speed or learn faster, thus relieving the managers from 'teaching tasks' allowing them to focus their time and energies on more important critical tasks, enhancing productivity. Similarly, best practices will be openly shared and spread though groups, and there will be enhanced team spirit, morale, and cohesiveness.

There is call for organizations to create workplaces which are free from fear, and are purposeful and recognize the inherent needs of its people. Workplace spirituality is the answer to one such call. As organizations operate on diminishing margins and success metrics are dependent on the scale of operations, successful organizations will need employees who will do more than their usual job duties and provide performance that is beyond expectations. Crawford et al. (2009) found that workplace spirituality impacts job satisfaction and they found that when the organization was actively promoting workplace spirituality, there is a significant difference compared to an organization that was perceived not to have incorporated spirituality, on the organizational level.

This research is important for businesses which want to create competence and organizational effectiveness. Indian contextual studies (non-western context) on both workplace spirituality and organizational outcomes are few and keeping in mind the growth of Indian industry, the evolving workforce and demands being made on workplaces, a study like this is significant. They state that businesses should act as agents of national progress and development, act as socially responsible citizens contributing to the environment and influence wellbeing. This would require a strong and hard look at current management practices. Allio (2011) states that as a result of the consequences of questionable and corrupt corporate practices, there is a strong need felt to articulate a new sense of purpose of the firm, corporate character and culture, survival, sustainability and innovation. Thaker (2011) advocates the same view as he states that the current management and organizational policies, principles and practices are focused on a view of self interest. This results in socially and environmentally dysfunctional organizations. An alternative approach is workplace spirituality (Al-Qutop \& Harrim, 2014). Al-Qutop and Harrim (2014) exhort that reinventing the ultimate mission and purpose of modern organizations has become a steady focus and point of attention today. Workplace spirituality can produce major benefits through the improvement of productivity, service quality, retention rates and overall corporate sustainability (Fawcett et al., 2008). A study of this nature will highlight the role of workplace spirituality in encouraging job stsifaction amongst its employees and how that job satisfaction may lead to them demonstrating pro-organization behaviors. 


\section{Conclusion}

In conclusion, workplace spirituality is gaining interest as a newer source of competitive advantage, and researchers are analyzing the antecedents and consequences of workplace spirituality. Studying workplace spirituality and the behaviors which emerge as a result, can lead to a better understanding of the actual status of the organizational climate. It can also reveal conditions under which employees display behaviors which will benefit themselves and the organization, critical elements to ensure competitive advantage. Workplace spirituality has also shown linkages to sustainable behavior and that is a key want from organizations today. This article has proposed the mediating role of job satisfaction between workplace spirituality and OCB. There are millions of dollars spent annually on increasing job satisfaction in workplaces and if some focus is given to the core components of workplace spirituality, which call for lesser external investments and more in belief systems, and behaviors, there will be much more to be gained.

\section{References}

Allio, R. (2011). Reinventing management purpose: The radical and virtuous alternatives. Strategy \& Leadership, 39(4), 4-11.

Al-Qutop, M., \& Harrim, H. (2014). Spiritual Organization: A Path to organizational Sustainable Excellence. Indian business Research, 7(8), 168-179.

Altaf, A., \& Awan, M. (2011). Moderating Affect of Workplace Spirituality on the relationship of Job Overload and Job Satisfaction. Journal of Business Ethics.

Ashmos, D., \& Duchon, D. (2000). Spirituality at Work. A Conceptualization and Measure. Journal of Management Inquiry, 9(2), 134-145.

Bateman, T., \& Organ, D. (1983). Job satisfaction and the good soldier: The relationship between affect and employee "citizenship". Academy of Management Journal, 26, 587-595.

Brown, R. (2003). Organizational Spirituality: The Sceptic's Version. Organization, 10, 393-400.

Bukhari, Z. (2008). Key Antecedents of Organizational Citizenship (OCB) in the banking Sector of Pakistan. International Journal of Business and Management, 3(12).

Chappell, T. (1994). The soul of a business: Managing for profit and the common good. New York: Bantam Books.

Chawla, V., \& Guda, S. (2010) Individual spirituality at work and its relationship with job satisfaction, pensity to leave and job commitment: an exploratory study among sales professionals. Journal of Human Values, 16, 157-167.

Crawford, E., LePine, J., \& Rich, B. (2010). Linking job demands and resources to employee engagement and burnout: A theoretical extension and meta-analytic test. Journal of Applied Psychology, 95(5), 834-848.

Duchon, D., \& Plowman, D. (2005). Nurturing the spirit at work: impact on work unit performance. The Leadership Quarterly, 16(5), 807-33.

employee "citizenship." Academy of Management Journal, 26, 587-595.

Fawcett, S., Brau, J., Rhoads, G., Whitlark, D., \& Fawcett, A. (2008). Spirituality and Organizational Culture: Cultivating the ABCs of an inspiring Workplace. International Journal of Public Administration, 31(4).

Fredrickson, B. (2004). The broaden and build theory of positive emotions. Philosophical Transactions of Royal Society, 359, 1367-1377.

Fry, L., Hannah, S., Noel, M., \& Walumbwa, F. (2011). Impact of spiritual leadership on unit performance. The Leadership Quarterly, 22(2), 259-270.

Gelfand, M., Erez, M., \& Aycan, Z. (2007). Cross-cultural organizational behavior. Annual Review of Psychology, $58(20), 1-35$.

Giacalone, R., \& Jurkiewicz, C. (2003). Handbook of workplace spirituality and organizational performance. Armonk, NY: M.E. Sharpe.

Hansen, M., \& Keltner, D. (2012). Finding Meaning at Work, Even when Your Job is Dull. HBR. Retrieved from https://hbr.org/2012/12/finding-meaning-at-work-even

Karambayya, R. (1989). Contexts for organizational citizenship behavior: Do high performing and satisfying units have better 'citizens. York University Working Paper, North York, Ontario, Canada. 
Katz, D., \& Kahn, R. (1978). The social psychology of organizations. New York.

Kinjerski, V., \& Skrypnek, B. (2004). Defining Spirit at Work: Finding Common Ground. Journal of organizational Change Management, 17(1), 26-42.

Komala, K., \& Ganesh, L. (2007). Individual spirituality at work and its relationship with job satisfaction and burnout: An exploratory study among healthcare professionals. The Business Review, 7(1), 124-129.

Krishnakumar, S., \& Neck, C. (2002). The "What", "Why", and "How" of Spirituality in the Workplace. Journal of Managerial Psychology, 17(3), 153-164.

MacKenzie, S., Podsakoff, P., \& Ahearne, M. (1998). Some possible antecedents of in-role and extra-role salesperson performance. Journal of Marketing, 62, 87-98.

Mahakul, P. (2015). Workplace Spirituality and Cultural Awakening of Western Bonai on Impact of Sarsara. American International Journal of Research in Humanities, 9(3), 284-290.

Milliman, J., Czaplewski, A., \& Ferguson, J. (2003). Workplace spirituality and employee work attitudes: An exploratory empirical assessment. Journal of Organizational Change Management, 16(4), 426-447.

Mitroff, I., \& Denton, E. (1999). A study of spirituality in the workplace. Sloan Management Review, 40, 83-92.

Nemeth, C., \& Staw, B. (1989). The tradeoffs of social control and innovation in small groups and rganizations. In L. Berkowitz (Ed.), Advances in experimental social psychology (Vol. 22, pp. 75-210). New York: Academic Press.

Organ, D. (1988). Organizational citizenship behavior: The good soldier syndrome. Lexington, MA: Lexington Books.

Overell, S. (2008). Inwardness: The rise of meaningful work. The work foundation. Provocation Series, 4(2).

Pawar, B. (2009). Some of the Recent Organizational Behavior Concepts as Precursors to Workplace Spirituality. Journal of Business Ethics, 88(2), 245-261.

Rastgar, D., Davoudi, S., Oraji, S., \& Abbasian, M. (2012). A Study of the Relationship Between Employees Spiritual Intelligence and Job Satisfaction: A Survey in Iran's Banking Industry. Spectrum, 1(2).

Sanders , J., Hopkins,W., \& Geroy, G. (2005). A causal assessment of the spirituality-leadership-commitment relationship. Journal of Management, Spirituality and Religion, 2, 39-66.

Setiyawati, D., \& Abdul Rahman, W. (2007). Spirituality and personality correlates of organizational citizenship behavior. In Third International Research Colloquium: Research in Malaysia and Thailand.

Sharma, J., Bajpai, N., \& Holani, U. (2011). OCB in Public and Private Sector and its Impact on Job Satisfaction: A Comparative study in Indian Perspective. International Journal of Business and Management, 6(1), 67-75.

Smith, A., Organ, D., \& Near, J. (1983). Organizational Citizenship Behaviors: Its Nature and Antecedents. Journal of Applied Psychology, 68(4), 653-663.

Smith, H. (1955). Psychology of Industrial Behaviour. New York: Mcgraw Hill

Stamp, K. (1991). Spirituality and environmental education. Australian Journal of Environmental Education, $7(1), 79-86$.

Thaker, K. (2009). Approaches to spirituality in business. Journal of Human Values, 15(2), 185-198.

Van Dyne, L., Graham, J., \& Dienesch, R. (1994). Organizational Citizenship Behavior: Construct Redefinition, Measurement, and Validation. The Academy of Management Journal, 37(4), 765-802

Zimmerman, E. (2004). The New York Times; The many delicate issues of spirituality in the Office.

\section{Copyrights}

Copyright for this article is retained by the author(s), with first publication rights granted to the journal.

This is an open-access article distributed under the terms and conditions of the Creative Commons Attribution license (http://creativecommons.org/licenses/by/3.0/). 